\title{
Blaming the balloon: the risk of post-intubation tracheobronchial rupture
}

\author{
Jennifer Richelle Reilly • Mathieu Pasquier • \\ Bertrand Yersin • Patrick Schoettker • \\ Pierre-Nicolas Carron
}

Received: 9 July 2013/Accepted: 21 August 2013/Published online: 31 August 2013

(C) SIMI 2013

Keywords Intubation - Tracheobronchial rupture . Airway management . Tracheal injury

\section{Case description}

The pre-hospital retrieval service attended the home of an 82 -year-old, $68 \mathrm{~kg}$ woman found unconscious with no evidence of trauma. Her airway was obstructed by vomit, oxygen saturation was $48 \%$ and Glasgow Coma Score was six. The pupils were small and reactive. A cerebrovascular accident was presumed. The airway was suctioned, followed by rapid sequence induction with etomidate and succinylcholine. Intubation was performed with a size 7 Mallinckrodt endotracheal tube (ETT) (Mallinckrodt ${ }^{\circledR}$ HiContour Oral Tracheal Tube Cuffed, Covidien llc, 15 Hampshire Street, Mansfield, MA 02048) containing a preformed stylet, which was removed once the ETT passed through the vocal cords. Post-intubation auscultation was

\section{J. R. Reilly}

Emergency Department and Anaesthesia Department, Lausanne

University Hospital, Lausanne, Switzerland

\section{J. R. Reilly}

Department of Anaesthesia, John Hunter Hospital, Newcastle, Australia

M. Pasquier · B. Yersin · P.-N. Carron ( $\varangle)$

Emergency Department, Lausanne University Hospital (CHUV),

1011 Lausanne, Switzerland

e-mail: pierre-nicolas.carron@chuv.ch

P. Schoettker

Anaesthesia Department, Lausanne University Hospital,

Lausanne, Switzerland symmetric, oxygen saturation rose to $95 \%$, and the ETT position was confirmed by capnography. No further drugs were administered for transfer while the hemodynamic profile was uneventful.

A CT brain scan was normal, while a cervico-thoracic CT scan revealed mediastinal emphysema predominant in the left para-tracheal region, subcutaneous emphysema of the neck and a sub-glottic ETT cuff measuring $3 \mathrm{~cm}$ in diameter. No pneumothorax was present. Lesions of the trachea or oesophagus were not demonstrated. Changes in the lung fields were suggestive of bronchoaspiration, and the patient subsequently developed acute respiratory distress syndrome. The initial chest radiograph is shown in Fig. 1.

While intubation had been uneventful, the patient was observed to cough vigorously on the ETT in the emergency department (ED), but administration of further sedation or neuromuscular blocking agent was withheld to allow subsequent neurological assessment. At this time, the Ambu ${ }^{\circledR}$ bag circuit in use had no expiratory valve.

Bronchoscopy showed an ETT tip $4 \mathrm{~cm}$ above the carina, food debris and purulent secretions at the carina and throughout the tracheobronchial tree. There was a $4 \mathrm{~cm}$ vertical tear of the posterior wall of the membranous trachea between the first and fifth tracheal rings. The ETT cuff was repositioned distal to the lesion. Surgical repair was not performed. Spontaneous tracheal healing on day 23 was confirmed by bronchoscopy, but the patient redeveloped pneumonia with no neurological improvement. An MRI imaging of the brain showed diffuse leucoencephalopathy, thought to be from hypoxia secondary to bronchoaspiration, on a background of dysphagia. After discussion with the family, treatment limits were agreed, and the patient subsequently died on day 40. 


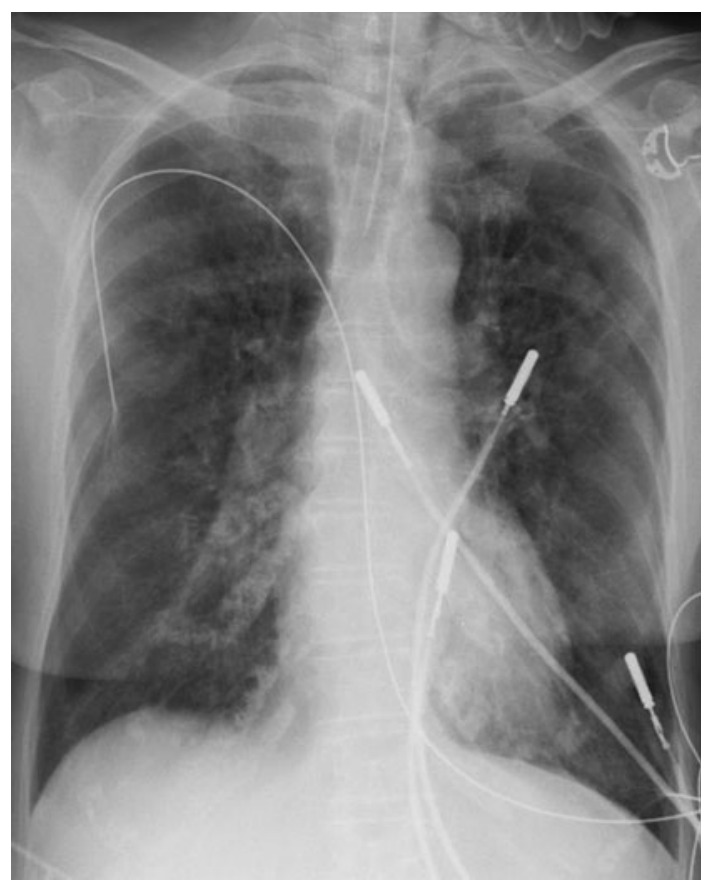

Fig. 1 Initial chest radiograph demonstrating endotracheal tube cuff overinflation and bronchoaspiration

\section{Discussion}

\section{Background and epidemiology}

Tracheobronchial rupture (TBR) may present following trauma, intubation, tracheal cannulation or positive pressure ventilation. Its potentially lethal sequelae include tension pneumothorax, mediastinitis, tracheal stricture and respiratory failure [1]. Iatrogenic rupture occurs more commonly than traumatic rupture [2], and its major cause is airway instrumentation, including intubation, tracheal cannulation or rigid bronchoscopy [3-5]. Airway procedures performed under emergency conditions pose a particular risk [2, 3, 611], and have an associated mortality up to four times greater following TBR resulting from elective procedures [11]. A closed claim analysis reveals that one-third of claims for tracheal injury are for tracheal rupture, mostly during routine intubation, and that delayed presentation of tracheal rupture is common [12]. Situational, mechanical and anatomical risk factors for post-intubation TBR are listed in Table 1. An incidence has not been reported for single-lumen tubes, but is $0.05-0.37 \%$ for double lumen tubes in an elective setting [13, 14]. Mortality relates to underlying disease rather than tracheal rupture [2].

\section{Pathophysiology}

Acute iatrogenic TBR may result from penetrating mechanisms such as direct perforation of the tracheal wall, or blunt mechanisms such as a sudden increase in trans-tracheal pressure resulting in separation of the membranous trachea. The majority of post-intubation tears are longitudinal, occur in the lower third of the trachea, and may extend into the main bronchi $[5,9]$, while tracheostomyassociated tears are often in the middle third of the trachea [5]. Post-intubation tears usually occur in the midline or on the right side of the membranous posterior wall of the thoracic trachea $[9,15]$. In traumatic TBR, tears from blunt trauma occur in the thoracic trachea, while tears from penetrating trauma occur commonly in the anterior extrathoracic trachea [4].

Intrathoracic tracheal rupture displaces air into the mediastinum, which redistributes at very low mediastinal pressures by dissection along fascial planes. It is thus uncommon in non-traumatic TBR to raise mediastinal pressure to the near $20 \mathrm{mmHg}$ pressure required to rupture the mediastinal pleura and cause a pneumothorax [16]. When a pneumothorax does occur, it is universally preceded by subcutaneous or mediastinal emphysema [4, 14]. Differential diagnoses of pneumomediastinum include rupture of other air-containing structures, such as the oesophagus or alveoli, by blunt chest trauma or positive pressure ventilation [14].

\section{Diagnosis}

The first signs of TBR may be clinical (Table 2) or radiological (Table 3). Diagnosis is confirmed by computed tomography or fibre-optic bronchoscopy [5]. The CT scan sensitivity for tracheal injury is $85 \%$ [4]. Bronchoscopy reveals the site and extent of tear, which in turn determine conservative or surgical management. Radiographic signs of TBR relate to overinflation of the ETT cuff, and thus increased cuff diameter, presence of air in the mediastinum, and possible abnormal ETT position (Table 3).

ETT cuff overinflation may occur when the presence of an existing rupture requires an increased amount of air in the cuff to seal the trachea. This occurs commonly in traumatic TBR [4]. The presence of cuff overinflation gives no indication as to mechanism or timing of TBR.

The average diameter of the human trachea is $2 \mathrm{~cm}$ in women, and $2.4 \mathrm{~cm}$ in men; a horizontal cuff diameter greater than $2.8 \mathrm{~cm}$, measured at the widest point, indicates likely rupture of the healthy trachea $[14,17]$. To estimate vertical cuff expansion, the distance between the inferior border of the cuff and the distal ETT tip is measured; it is normally more than $2.5 \mathrm{~cm}$ [14]. A reduction in this distance may indicate cuff overinflation with or without TBR, or cuff anchoring following ETT repositioning with inadequate cuff deflation [14]. One case series of post-intubation TBR reports cuff diameters of $2.8-4.3 \mathrm{~cm}$ and cuff-to- 
Table 1 Risk factors for post-intubation tracheal rupture from single-lumen tubes $[3,5,6,10,11,21,22]$

\begin{tabular}{|c|c|c|}
\hline Situational & Mechanical & Anatomical \\
\hline Pre-hospital or emergency setting & Multiple vigorous intubation attempts & Female \\
\hline Operator inexperience & Stylet protruding from ETT & Short stature \\
\hline \multirow[t]{11}{*}{ Unsuccessful intubation attempts } & Malposition of ETT tip & $\begin{array}{l}\text { Congenital tracheal abnormalities } \\
\text { (e.g. tracheomalacia) }\end{array}$ \\
\hline & Inadequate tube size & $\begin{array}{l}\text { Weakness of membranous trachea (e.g. chronic } \\
\text { steroid use, chronic obstructive pulmonary disease) }\end{array}$ \\
\hline & Rapid cuff inflation & Inflammatory lesions of tracheobronchial tree \\
\hline & Cuff overinflation & $\begin{array}{l}\text { Large mediastinal collections, lymph nodes or } \\
\text { neoplasms distorting trachea }\end{array}$ \\
\hline & Repositioning ETT with inadequate cuff deflation & \\
\hline & Vigorous coughing on ETT & \\
\hline & Abrupt head/neck movement while intubated & \\
\hline & Moving patient while cuff inflated & \\
\hline & $\mathrm{N}_{2} \mathrm{O}$ diffusion into cuff & \\
\hline & $\begin{array}{l}\text { Positive pressure ventilation or oxygen flush against } \\
\text { closed expiratory valve }\end{array}$ & \\
\hline & $\begin{array}{l}\text { Direct connection of pilot balloon to pressurised } \\
\text { oxygen }\end{array}$ & \\
\hline
\end{tabular}

Table 2 Clinical signs of tracheal rupture $[3,5,15]$

\section{Respiratory distress}

Difficult ventilation

Persistent air leak around ETT despite adequate cuff inflation

Cyanosis

Haemoptysis

Mediastinal emphysema

Subcutaneous emphysema

Pneumothorax

Table 3 Radiological signs of tracheal rupture [15]

1. Overdistended endotracheal tube cuff, with tube tip oriented to right

Cuff diameter $>2.8 \mathrm{~cm}$

Cuff to distal ETT tip distance $<2.5 \mathrm{~cm}$

Increasing intratracheal diameter compared with previous imaging

2. Air in surrounding structures

Deep cervical emphysema, paratracheal air, subcutaneous emphysema

Pneumomediastinum, pneumothorax

Pneumoperitoneum, pneumoretroperitoneum

3. Tracheal wall abnormality or extratracheal ETT location

Tracheal wall deformity, defect, discontinuity extending above or below carina

Extratracheal location of ETT tip or herniated cuff tip distances of $0-1.2 \mathrm{~cm}$ [14]. Cuff inflation to $6.5 \mathrm{~cm}$ diameter has been reported [6]. Differential diagnoses of an overinflated ETT cuff on imaging include TBR, oesophageal ETT placement, simple cuff overinflation, or disease causing tracheal enlargement or dilatation [14].

Mechanisms of endotracheal tube cuff-related TBR

Early reports of post-intubation TBR relate to the first generation of cuffed ETTs. These cuffs were poorly compliant (low volume-high pressure), required inflation pressures of over $180 \mathrm{mmHg}$, created a seal by deforming the trachea, and inflated asymmetrically, directing the ETT tip against the tracheal wall [18]. As cuff design evolved, these were followed by the first high volume-low pressure cuffs, but both types could easily be filled with $60 \mathrm{ml}$ air, producing a cuff distended greater than $4 \mathrm{~cm} \mathrm{[14].}$ Numerous reports were made of post-intubation TBR likely resulting from cuff overinflation $[3,19,20]$.

Modern high volume-low pressure ETT cuffs are highly compliant, and conform to the shape of the trachea rather than deform it. Their symmetric inflation directs the ETT tip to the central trachea rather than its wall, and a seal is achieved with inflation pressures of $<30 \mathrm{cmH}_{2} \mathrm{O}$ [17]. One proposed mechanism of post-intubation TBR commences with accidental initial right main bronchus intubation, requiring large air volumes to seal a cuff inadvertently located at the carina, detection of the error by auscultation, 
followed by ETT withdrawal into the narrower lower trachea with incomplete or absent cuff deflation, which overstretches the membranosa [5]. Patients of short stature are at particular risk of right main bronchus intubation [5].

In cadaver studies with modern Mallinckrodt singlelumen ETTs, cuff pressure required to rupture the intubated healthy trachea is extremely high $\left(>120 \mathrm{cmH}_{2} \mathrm{O}\right)$, and rupture is difficult to achieve, requiring a corresponding cuff volume of $75 \mathrm{ml}$ [4]. There is a marked increase in resistance to further inflation of the cuff after injection of $50 \mathrm{ml}$ air, highlighting the physical difficulty of achieving a cuff pressure or volume sufficient to cause tracheal rupture [4]. The tissue properties of cadaver trachea differ from living trachea, and these studies have not been replicated in the living trachea. Although cuff overinflation continues to be reported as a cause of post-intubation TBR in the literature [5, 8], cadaver studies suggest that this may be unlikely with modern single-lumen ETTs in the healthy trachea, within the limits of simple accidental overinflation by hand [4].

Our female patient was intubated under emergent conditions in the pre-hospital setting with the aid of a stylet, by an experienced pre-hospital emergency doctor. She was ventilated by positive pressure, coughed vigorously on the ETT, and was transferred between different beds on multiple occasions intubated with the cuff inflated. She did not have any other risk factors described for TBR. There is insufficient evidence to determine whether overinflation of the ETT cuff caused tracheal rupture; it is possible that coughing on the ETT with no expiratory valve in the circuit whilst awaiting neurological assessment was the cause. Alternative causes may include direct trauma from the ETT tip or stylet at intubation or during transfer of a critically ill patient.

\section{Conclusion}

This Mortality and Morbidity case highlights several important points and demonstrates many of the risk factors for intubation-related tracheal rupture. Coughing on an endotracheal tube may put the trachea at risk of rupture, and should be treated by sedation or paralysis. Mechanical forces associated with intubation remain a likely cause of intubation-related tracheal rupture. There is insufficient evidence in the literature to conclude that simple accidental cuff overinflation, as might occur in routine clinical practice, causes rupture of the healthy trachea with modern high volume-low pressure cuffed single-lumen tubes.

\section{References}

1. Smith B, Hopkinson R (1984) Tracheal rupture during anaesthesia. Anaesthesia 39:894-898

2. Hofmann HS, Rettig G, Radke J, Neef H, Silber RE (2002) Iatrogenic ruptures of the tracheobronchial tree. Eur J Cardiothorac Surg 21:649-652

3. Orta DA, Cousar J, Yergin B, Olsen GN (1979) Tracheal laceration with massive subcutaneous emphysema: a rare complication of endotracheal intubation. Thorax 34:665-669

4. Chen J, Shanmuganathan K, Mirvis S, Killeen K, Dutton R (2001) Using CT to diagnose tracheal rupture. AJR 176:1273-1280

5. Massard G, Rougé C, Dabbagh A, Kessler R, Hents JG, Roeslin $\mathrm{N}$ et al (1996) Tracheobronchial lacerations after intubation and tracheostomy. Ann Thorac Surg 61:1483-1487

6. Harris R, Joseph A (2000) Acute tracheal rupture related to endotracheal intubation. J Emerg Med 18:35-39

7. Sternfeld D, Wright S (2003) Tracheal rupture and the creation of a false passage after emergency intubation. Ann Emerg Med 42:88-92

8. Fan C, Ko P, Tsai K, Chiang W, Chang Y, Chen W et al (2004) Tracheal rupture complicating emergent endotracheal intubation. Am J Emerg Med 22:289-293

9. Sippel M, Putensen C, Hirner A, Wolff M (2006) Tracheal rupture after endotracheal intubation: experience with management in 13 cases. Thorac Cardiov Surg 54:51-56

10. Medina C, Camargo J, Felicetti J, Machuca T, Gomes B, Melo I (2009) Post-intubation tracheal injury report of three cases and literature review. J Bras Pneumol 35:809-813

11. Conti M (2006) Management of postintubation tracheobronchial ruptures. Chest 130:412-418

12. Domino KB, Posner KL, Caplan RA, Cheney FW (1999) Airway injury during anesthesia: a closed claims analysis. Anesthesiology 91:1703-1711

13. Personne C, Kleinmann P, Bisson A, Toty L (1987) Les déchirures trachéo-bronchiques par tube de Carlens. Ann Chir 41:494-497

14. Spaggiari L, Rusca M, Carbognani P, Solli P (1998) Tracheobronchial laceration after double-lumen intubation for thoracic procedures. Ann Thorac Surg 65:1837

15. Rollins RJ, Tocino I (1987) Early radiographic signs of tracheal rupture. AJR 148:695-698

16. Webb W, Johnston J, Geisler J (1958) Pneumomediastinum: physiological observations. J Thorac Surg 35:309-315

17. Mackenzie C, Shin B, Whitley N, Helrich M (1980) Human tracheal circumference as an indicator of correct cuff size. Anesthesiology 53:S414

18. Cooper JD, Grillo HC (1972) Analysis of problems related to cuffs on intratracheal tubes. Chest 62:21S-27S

19. Santy P, Couniot J (1955) Rupture de la trachée au cours d'une anesthésie avec intubation par sonde à ballonnet. Lyon Chir 50:104

20. Eaton J (1985) Tracheal rupture. Anaesthesia 40:212

21. Tornvall SS, Jackson KH, Enrique TO (1971) Tracheal rupture, complication of cuffed endotracheal tube. Chest 59:237-239

22. de Lange J, Booij L (1985) Tracheal rupture. Anaesthesia $40: 211-212$

\section{Conflict of interest None.}

